\title{
POTENTIOMETRIC TITRATION CURVES OF ALUMINIUM SALT SOLUTIONS AND ITS SPECIES CONVERSION IN THE HYDROLYSIS-POLYMERIZATION COURSE
}

\author{
Chenyi Wang ${ }^{\mathrm{a}^{*}}$, Zhiping Han ${ }^{\mathrm{a}}$, Ping Wang ${ }^{\mathrm{b}}$, Nan Cui ${ }^{\mathrm{a}}$ Tingjun Lao $^{\mathrm{a}}$ and Peiqin Hong ${ }^{\mathrm{a}}$ \\ ${ }^{a}$ Department of Chemistry, Huzhou University, Huzhou 313000, China \\ ${ }^{\mathrm{b}}$ Colleges of Chemical Engineering, Nanjing Forestry University, Nangjing 210037, China
}

(Received May 8, 2007; revised February 19, 2008)

\begin{abstract}
A new concept of critical point is expounded by analysing the potentiometric titration curves of aluminium salt solutions under the moderate slow rate of base injection. The critical point is defined as the characteristic spot of the $\mathrm{Al}^{3+}$ salt solutions potentiometric titration curve, which is related to the experiment conditions. In addition, the changes of critical points reflect the influence of experiment conditions on the course of the hydrolysis-polymerization and the conversion of hydroxyl polynuclear aluminum species. According to the $\mathrm{OH} / \mathrm{Al}$ mole ratio, the $\mathrm{Al}$ species can be divided into four regions quantitatively by three characteristic points on the titration curves: Part $\mathrm{I}, \mathrm{Al}^{3+} / \mathrm{Al}_{\mathrm{a}}$ region, consist chiefly of $\mathrm{Al}^{3+}$ and mononuclear $\mathrm{Al}$; Part II, the small/middle polynuclear $\mathrm{Al}$ region, including $\mathrm{Al}_{2}-\mathrm{Al}_{12}$; Part III, the large-size polynuclear aluminum region, consistent with predominantly $\mathrm{Al}_{13}-\mathrm{Al}_{54}$ and a little sol/gel $\mathrm{Al}(\mathrm{OH})_{3}$; Part IV, the dissolving region of sol/gel $\mathrm{Al}$, only $\mathrm{Al}(\mathrm{OH})_{3}$ (aq or am) and $\mathrm{Al}(\mathrm{OH})_{4}{ }^{-}$species, which set up a base to study on the hydrolysis-polymerization of $\mathrm{Al}^{3+}$. At the same time, significant effects of total aluminum concentration, temperature, halide ion, silicate radical, and organic acid radical on the titration curves and its critical points were observed. Given the three critical points which demarcating the aluminum forms, we carry out a through investigation into the fundamental regulations of these factors' influence, and offer a fresh train of thought to study the hydrolysis-polymerization of $\mathrm{Al}^{3+}$ in soil solutions.
\end{abstract}

KEY WORDS: Potentiometric titration, Hydroxyl polynuclear aluminum species, Hydrolysis-polymerization, Critical point, Factors affecting titration curves

\section{INTRODUCTION}

At the present time, the environmental acidification and a great deal of using polynuclear $\mathrm{Al}$ coagulant are believed to be due to the increasing concentration of hydroxyl aluminum in natural waters and drinking water. As an intermediate product of the hydrolysis of Al solutions, the hydroxyl polynuclear $\mathrm{Al}$ species is even more toxic than $\mathrm{Al}^{3+}$ and mononuclear $\mathrm{Al}$ [1-3]. However, many people are still short of a definite recognition of the hydroxyl polynuclear complexes and their formation mechanisms, the morphological structures, the physicochemical properties and the reaction mechanisms in their applied courses [4-11], which is mainly on account of the complication in the hydrolysis-polymerization reaction of $\mathrm{Al}^{3+}$ and its formed species, meanwhile, due to the numerous influential factors on the conversion of the Al species and the complicated composition of the products [12], including concentration, temperature, complex ion, mole ratio of $\mathrm{OH}^{-}$to $\mathrm{Al}^{3+}$ (namely $\mathrm{OH} / \mathrm{Al}$, termed as $\mathrm{n}$ ) and aging period [13]. The potentiometric titration is a basic method of exploring the conversion of $\mathrm{Al}$ species in the hydrolysis-polymerization. Since a long period of time, as a result of deficiency in quantitative description about the potentiometric titration curves, and the dissimilar experiment conditions, it aroused a lot of controversy and it is difficult to compare each other. By analysing the simplest titration ( $\mathrm{pH}$ vs $\mathrm{n}$ ) curves as a first point, the study reported here focuses on the conversion trends of the species in the hydrolysis-polymerization of $\mathrm{Al}^{3+}$, and attempts to investigate the effects of various factors on the titration $\mathrm{pH}$ vs $\mathrm{n}$ curves, as well as discussing the influences of above factors in the hydrolysis-polymerization course of aluminum salt solutions.

*Corresponding author. E-mail: chenyi_wang@163.com 


\section{EXPERIMENTAL}

\section{Reagents and apparatus}

$0.5 \mathrm{M} \mathrm{AlCl}_{3}$ and $1 \mathrm{M} \mathrm{NaOH}$ stock solution were prepared with corresponding reagents dissolving in double-deionised water which had been thoroughly purged with high purity $\mathrm{N}_{2}$. The operating solutions were both diluted from their stock solutions, and their concentration should be equal as far as possible. In addition, all the standard solution should be freshly prepared, and the chemicals used in all experiments were in analytical reagent grade. Both the experimental water and the preparation water were all the double-distilled water in $\mathrm{CO}_{2}$-free. Withal, all the solutions were stored in acid-soaked polyethylene containers. In order to avoid activity coefficient variations, a continuous ionic medium of $\mathrm{KCl}$ was used as the background electrolyte. The ZD-2 type digital automatic titrator (Shanghai) accompanied with ultra thermostat, JB-1A style electromagnetic stirrer, and a combination glass-calomel electrode were used to inject $\mathrm{NaOH}$ titrant and record $\mathrm{pH}$ value automatically. The electrode has been rectified according to Irving [11].

\section{The potentiometric titration experiment}

In the experiment, $25 \mathrm{~mL} \mathrm{AlCl}{ }_{3}$ standard solution was transferred into the double-decked insulated tumbler, which was added with a cover and a hole. Through the hole, alkali dropped into the Al salt solution with a Teflon capillary tube which is submerged in $30 \mathrm{~cm}$ of the solution under violently agitated, and the injecting rate was $0.8 \mathrm{~mL} \cdot \mathrm{min}^{-1}$. The mole ratio of $\mathrm{OH} / \mathrm{Al}$ increased 0.125 every time with injecting $\mathrm{NaOH}$ standard solution slowly until the number of $n=4$. From beginning to end, nitrogen was continually bubbled through the solution to remove inorganic carbon. The temperature of the experiment is controlled at $(25 \pm 0.5)^{\circ} \mathrm{C}$.

\section{RESULTS AND DISCUSSION}

The fraction and distribution of hydroxyl polynuclear Al species, and the analysis of potentiometric titration $\mathrm{pH}$ vs $n$ curves with respect to hydrolysis-polymerization of $\mathrm{Al}^{3+}-$ four regions/ three characteristic points

So far, for the studies on potentiometric titration of Al salt solution, people mainly focused on the relationship between the $\mathrm{n}$ and the species of polynuclear $\mathrm{Al}$, as well as the conjecture about the polynuclear Al species, while the invitable connection between the changes of critical characteristic points of the curves and the conversion of $\mathrm{Al}$ species was neglected. Referring to potentiometric titration experimental method, we found that there are 3 characteristic points which are noted as $\mathrm{A}\left(\mathrm{n}_{\mathrm{A}}, \mathrm{pH}_{\mathrm{A}}\right), \mathrm{B}\left(\mathrm{n}_{\mathrm{B}}, \mathrm{pH}_{\mathrm{B}}\right)$ and $\mathrm{C}\left(\mathrm{n}_{\mathrm{C}}, \mathrm{pH}_{\mathrm{C}}\right)$, respectively (Figure 1) on the base titration curve when titrating $\mathrm{Al}$ solutions with base under the medium rate of injecting base. These characteristic points are obtained from mathematical fitting on titration curve, due to the curve according with Boltzmann distribution. In which, the critical point is the crossing point of two neighbouring tangent lines passing through inflection point on it, while the inflection point is where the second derivative's value is zero on titration curve equation. 


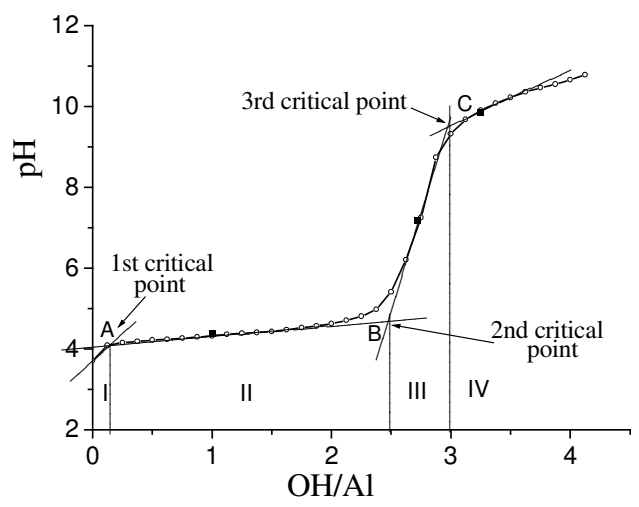

Figure 1. The base titration curve ( $\mathrm{pH}$ vs $\mathrm{OH} / \mathrm{Al}$ or $\mathrm{n}$ ) and the differentiation of polynuclear $\mathrm{Al}$ species under the moderate rate of injecting base (four regions/three critical characteristic points). $\left(\mathrm{AlCl}_{3}=0.005 \mathrm{M} ; \mathrm{NaOH}=0.01 \mathrm{M}\right.$; Ionic strength $\left.\mathrm{I}=0.02 \mathrm{M}\right)$.

These three critical points (A, B, C) express different meanings, respectively: At the first critical point $\mathrm{A}(\mathrm{n}=0.2)$, a lot of mononuclear $\mathrm{Al}$ begin to convert into small/middle polynuclear $\mathrm{Al}$ (oligomer). At the second critical point $\mathrm{B}(\mathrm{n}=2.5)$, it is very likely that the small/middle polynuclear Al begin to form large polynuclear Al. At the third critical point $\mathrm{C}$ ( $\mathrm{n}$ $=3.0$ ), the amorphous gel or sediment have appeared. In another word, the $\mathrm{OH} / \mathrm{Al} \mathrm{vs} \mathrm{pH}$ curve can be divided into four regions quantitatively by these three critical points (Figure 1). In the meantime, detailed exposition about the analysis of titration $\mathrm{pH}$ vs $\mathrm{n}$ curves and the critical points can be found in the disquisition [14].

It is established that the fraction of hydroxyl aluminum be in accord with some earlier work [15-17]. Generally speaking, the critical point is the characteristic point of the titration curve related to $\mathrm{Al}$ salt solution in the hydrolysis-polymerization course, which is related to experiment conditions. The change of critical point reflects the enormous effect of the different experiment conditions on the hydrolysis-polymerization course of $\mathrm{Al}$ salt solution and the conversion with respect to the species of hydroxyl polynuclear aluminum.

Effects of various factors on the potentiometric titration $p H$ vs $n$ curves and on the hydrolysispolymerization species of Al salt solution

It has been shown that there is a multiplicity of factors affecting the hydrolysis-polymerization course of Al salt solution and the conversion of $\mathrm{Al}$ species. The shape of the potentiometric titration $\mathrm{pH}$ vs $\mathrm{n}$ curves and the change of its critical point are obviously different in the dissimilar experiment conditions and extraneous factors. The shape of the $\mathrm{pH}$ vs $\mathrm{n}$ curves and the changing tendency of the critical point reflect the conversion course of polynuclear $\mathrm{Al}$ species. In a later part, we will quantitatively illustrate the effects of various factors on the hydrolysis-polymerization course of $\mathrm{Al}$ salt solution and on the conversion regulations of $\mathrm{Al}$ species along with the change of the critical point, the concentrations of $\mathrm{Al}$, the temperature, the halide ion, the silicate radical and the organic acid radical, etc.

Effects of the total concentration of Al(III)

Figure 2 shows the titration curves at four different concentrations of $\mathrm{AlCl}_{3}$ solution. During these experiments, we found that the solutions became turbid when the concentration of $\mathrm{Al}$ is 
higher than $0.05 \mathrm{M}$ and the value of $\mathrm{n}$ is about 2.6. However, in $0.5 \mathrm{M} \mathrm{AlCl}_{3}$ solution, white turbidity appears immediately as soon as the base is added because of partial oversaturation, and the amount of white flocculent precipitate increased with the $\mathrm{n}$ value. The formation of the precipitate accords with the solubility product rule of $\mathrm{Al}(\mathrm{OH})_{3}\left(\mathrm{~K}_{\mathrm{sp}}=10^{-34.5}\right.$ at $\left.25^{\circ} \mathrm{C}\right)$. With the increase of the total $\mathrm{Al}(\mathrm{III})$ concentration, the degree of hydrolysis of $\mathrm{Al}^{3+}$ decreases, while the $\mathrm{pH}$ value of the solution fall sharply due to the increasing of the total amount of hydrolysed $\mathrm{Al}$. Furthermore, the change of $\mathrm{pH}$ value will cause the alteration of the critical point on $\mathrm{pH}$ vs $\mathrm{n}$ curve and affect the size and the content of polynuclear $\mathrm{Al}$ species directly. It is concluded from the Figure 2 that:

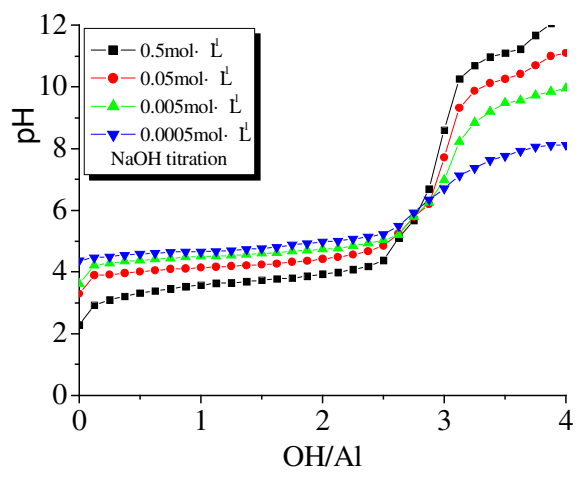

Figure 2. Effects of total $\mathrm{Al}(\mathrm{III})$ concentration $(0.5-0.0005 \mathrm{M})$ on the titration curves and critical points.

1) By comparison with the tiny influence of the concentration of $\mathrm{Al}$ on the transfer of $\mathrm{n}_{\mathrm{A}}$ and $\mathrm{n}_{\mathrm{C}}$, the second critical point $n_{B}$ is greatly disturbed (see Table 1 ). The range of the $n_{B}$ value in which polynuclear $\mathrm{Al}$ formed extended with the concentration increasing, and consequently made the corresponding curve in region III comparatively steep. All the above indicates that the higher the concentration, the narrower the range of $\mathrm{OH} / \mathrm{Al}$ mol ratio in which high polymer comes out, whereas the broader range of $\mathrm{OH} / \mathrm{Al}$ mol ratio in which low polynuclear $\mathrm{Al}$ species occur. It is established that the added $\mathrm{OH}^{-}$is mainly used to form polynuclear $\mathrm{Al}$ when the concentration of $\mathrm{Al}^{3+}$ is comparatively low, which makes the $\mathrm{pH}$ vs $\mathrm{n}$ curve very flat. It is indicated that the lower the concentration within a certain range, the more helpful for the hydrolysis-polymerization of $\mathrm{Al}^{3+}$.

2) In view of the $\mathrm{pH}$ value's change on the titration curve in longitudinal direction, the higher the concentration of $\mathrm{Al}$, the lower the $\mathrm{pH}$ in region II, on the contrary, the higher the $\mathrm{pH}$ in region III and region IV. It's clear that it is helpful for the hydrolysis-polymerization of $\mathrm{Al}$ and the formation of oligomeric $\mathrm{Al}$ species in the lower $\mathrm{n}$ value, and less helpful for the hydrolysispolymerization of $\mathrm{Al}$ in the high $\mathrm{n}$ value, which causes the formation of sol/gel $\mathrm{Al}_{\mathrm{c}}$.

3 ) The shapes of titration curves are slightly altered in the different concentrations of $\mathrm{Al}$. We can see that there is a crossing point close to about $n=2.7$ among the four curves of different concentrations of $\mathrm{Al}^{3+}$, which indicates that a relatively stable polynuclear $\mathrm{Al}$ species is formed in this spot, and the stable polymer may be a soluble polynuclear $\mathrm{Al}$ species, such as $\mathrm{Al}_{13}(\mathrm{OH})_{34}{ }^{5+}(\mathrm{n}=2.62), \mathrm{Al}_{13}(\mathrm{OH})_{35}{ }^{4+}(\mathrm{n}=2.69)$ or $\mathrm{Al}_{13}(\mathrm{OH})_{36}{ }^{3+}(\mathrm{n}=2.77)$, etc. 
Table 1. Changes of critical points demarcating $\mathrm{Al}$ form under the different $\mathrm{Al}^{3+}$ concentration.

\begin{tabular}{|c|c|c|c|c|c|c|c|}
\hline $\begin{array}{c}\text { Concentration of } \\
\mathrm{Al}^{3+}(\mathrm{M})\end{array}$ & \multicolumn{2}{|c|}{$\begin{array}{c}\text { First } \\
\text { critical point }\end{array}$} & \multicolumn{2}{c|}{$\begin{array}{c}\text { Second } \\
\text { critical point }\end{array}$} & \multicolumn{2}{c|}{$\begin{array}{c}\text { Third } \\
\text { critical point }\end{array}$} & \multirow{2}{*}{$\begin{array}{c}\text { Concentration } \\
\text { of } \mathrm{OH}^{-}(\mathrm{M})\end{array}$} \\
\cline { 2 - 7 } & $\mathrm{n}_{\mathrm{A}}$ & $\mathrm{pH} \mathrm{H}_{\mathrm{A}}$ & $\mathrm{n}_{\mathrm{B}}$ & $\mathrm{pH}_{\mathrm{B}}$ & $\mathrm{n}_{\mathrm{C}}$ & $\mathrm{pH}_{\mathrm{C}}$ & \\
\hline 0.5 & 0.17 & 3.3 & 2.8 & 4.2 & 3.0 & 9.7 & 1 \\
\hline 0.05 & 0.19 & 3.9 & 2.7 & 4.5 & 3.0 & 9.6 & 0.1 \\
\hline 0.005 & 0.20 & 4.1 & 2.5 & 4.7 & 3.0 & 9.3 & 0.01 \\
\hline 0.0005 & 0.24 & 4.4 & 2.5 & 5.1 & 3.1 & 8.1 & 0.001 \\
\hline
\end{tabular}

Effects of the temperature

The temperature affects the hydrolysis-polymerization course, the speciation distribution of $\mathrm{Al}^{3+}$, and the $\mathrm{pH}$ values of solutions [18-21]. It is observed that the initial $\mathrm{pH}$ values of $0.005 \mathrm{M} \mathrm{AlCl}_{3}$ solution are $3.74,3.69$ and 3.41 , respectively, at the temperatures of $25^{\circ} \mathrm{C}, 35^{\circ} \mathrm{C}$ and $55^{\circ} \mathrm{C}$.

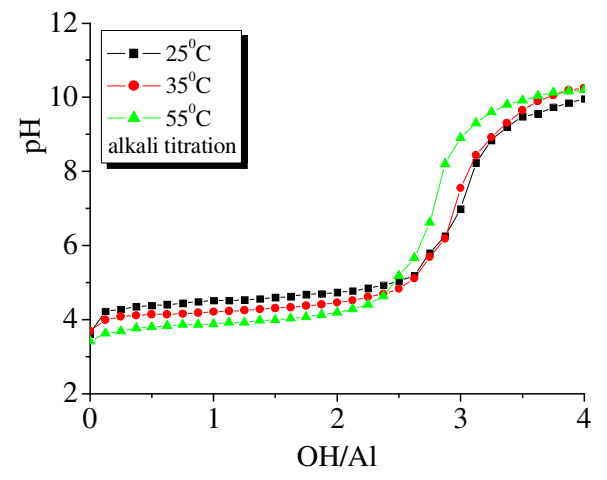

Figure 3. Effect of temperature on the titration curves $\left(\mathrm{AlCl}_{3}=0.005 \mathrm{M}, \mathrm{NaOH}=0.01 \mathrm{M}\right)$.

Figure 3 indicates that:

1) The effects of temperature on $n_{A}, n_{B}$ and $n_{C}$ are relatively slight (Table 2), which briefly indicate that the effects on the shape of titration curve and on the conversion of polynuclear $\mathrm{Al}$ species are comparatively small. In addition, the temperature mainly affects the conversion rate of polynuclear $\mathrm{Al}$ species.

Table 2. Effect of temperature on the potentiometric titration curves and its critical points $\left(\mathrm{AlCl}_{3}=0.005\right.$ $\mathrm{M}, \mathrm{NaOH}=0.01 \mathrm{M})$.

\begin{tabular}{|c|c|c|c|c|c|c|}
\hline $\begin{array}{c}\text { Temperature } \\
\left({ }^{\circ} \mathrm{C}\right)\end{array}$ & \multicolumn{2}{|c|}{ First critical point } & \multicolumn{2}{c|}{ Second critical point } & \multicolumn{2}{c|}{ Third critical point } \\
\cline { 2 - 7 } & $\mathrm{n}_{\mathrm{A}}$ & $\mathrm{pH}_{\mathrm{A}}$ & $\mathrm{n}_{\mathrm{B}}$ & $\mathrm{pH}_{\mathrm{B}}$ & $\mathrm{n}_{\mathrm{C}}$ & $\mathrm{pH}_{\mathrm{C}}$ \\
\hline 25 & 0.20 & 4.1 & 2.5 & 4.7 & 3.0 & 9.3 \\
\hline 35 & 0.19 & 4.0 & 2.6 & 4.5 & 3.1 & 8.6 \\
\hline 55 & 0.19 & 3.7 & 2.5 & 4.2 & 3.1 & 9.5 \\
\hline
\end{tabular}

2) The higher the temperature, the lower the $\mathrm{pH}$ values in the former section (i.e., region II) of titration curve, which indicates that the hydrolysis degree of $\mathrm{Al}^{3+}$ is high in this interval [18]. That is to say, increasing the temperature takes a positive effect on the hydrolysispolymerization of $\mathrm{Al}^{3+}$ and the formation of small/middle polynuclear $\mathrm{Al}$ species. On the contrary, the higher temperature, the higher the $\mathrm{pH}$ values in the latter section (region III and

Bull. Chem. Soc. Ethiop. 2008, 22(2) 
region IV) of curve, and the range of $\mathrm{Al}_{\mathrm{c}}$ comparatively extends, but the range of $\mathrm{Al}_{\mathrm{b}}$ shrinks, which indicates that the increasing of the temperature doesn't make a contribution to the formation of large polynuclear $\mathrm{Al}$ species, in the opposite, it accelerates large polymeric $\mathrm{Al}$ species converting into sol/gel of $\mathrm{Al}_{\mathrm{c}}$.

3) At higher temperature, the structural unit of metastable polynuclear $\mathrm{Al}\left(\mathrm{Al}_{\mathrm{b}}\right)$ is correspondingly small on account of its instability. However, even if the large polymer formed, there's a trend for it converts into oligomer or gel $\mathrm{Al}_{\mathrm{c}}$. These results confirm that it is very difficult for large polymer to exist stably in high temperature, yet the deprotonation accompanied with the deposition is more obvious [5].

\section{Effects of the halide ion $(\mathrm{F}, \mathrm{Cl}, \mathrm{Br}, \mathrm{I})$}

The $\mathrm{pH}$ vs $\mathrm{n}$ curve shape has great discrepancy as a result of the different kinds and the varied concentration of complexing ions. Furthermore, the titration curve is no longer an inverted "Sshape" when the concentration of complexing ion exceeds a certain value. In another word, the change of the curve shape and the critical point on the curve reflect the abilities of the complexing ions to bond with $\mathrm{Al}^{3+}$ when they compete with $\mathrm{OH}$. Figure 4 shows titration curves obtained from experiments when adding solid $\mathrm{NaF}, \mathrm{NaCl}, \mathrm{NaBr}$, and $\mathrm{NaI}$ into $0.005 \mathrm{M} \mathrm{AlCl}_{3}$ solution, respectively. It can be seen from the figure that:

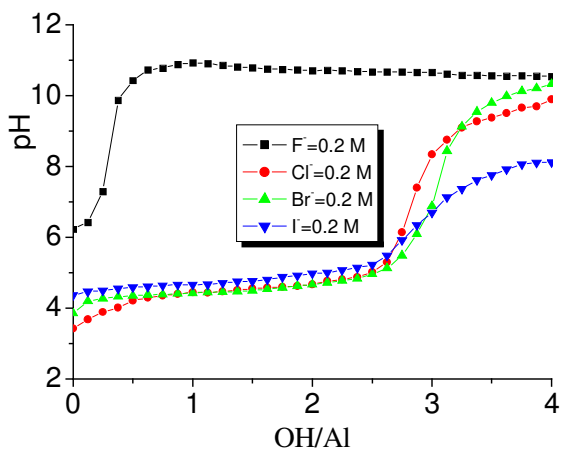

(A)

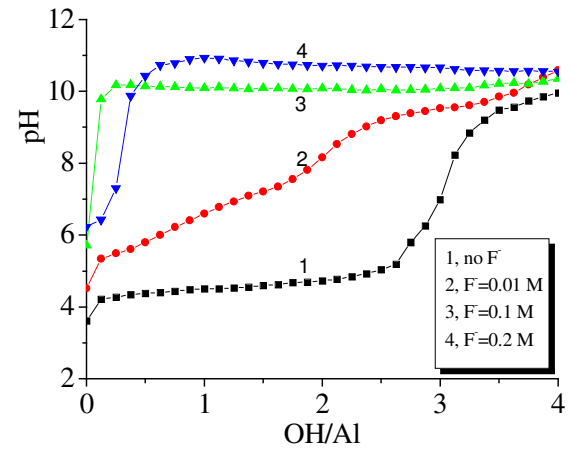

(B)

Figure 4. Effects of $\mathrm{F}^{-} \mathrm{Cl}^{-}, \mathrm{Br}^{-}, \mathrm{I}^{-}$and the consumption of $\mathrm{NaF}$ on the $\mathrm{pH}$ vs $\mathrm{n}$ titration curves $\left(\mathrm{AlCl}_{3}=0.005 \mathrm{M}, \mathrm{NaOH}=0.01 \mathrm{M}\right)$.

1) The effects of $\mathrm{Cl}^{-}, \mathrm{Br}^{-}$and $\mathrm{I}^{-}$on the three critical points are much smaller than that of $\mathrm{F}$. Furthermore, the abilities of halide ions to affect the hydrolysis-polymerization of $\mathrm{AlCl}_{3}$ solution decreases in the sequence of $\mathrm{F}, \mathrm{Cl}^{-}, \mathrm{Br}^{-}, \mathrm{I}^{-}$[22], which is by virtue of the differences in the structures and the properties of respective ions. From $\mathrm{F}$ to $\mathrm{I}$, hard base transfers to soft base. According to the theory of hard and soft acids and bases (HSAB), $\mathrm{Al}^{3+}$ ion belongs to hard acid, and the affinity between $\mathrm{F}$ and $\mathrm{Al}^{3+}$ is the strongest among halide ions, so the competitive ability of $\mathrm{F}$ to $\mathrm{OH}^{-}$in polynuclear $\mathrm{Al}$ molecule is the strongest, furthermore, the effect on the hydrolysis-polymerization course of $\mathrm{Al}^{3+}$ is also the greatest, while the responding effects of $\mathrm{I}$ is the slightest. For the position of $\mathrm{Cl}^{-}, \mathrm{Br}^{-}$and $\mathrm{I}^{-}$which are located on the coordination external of the hydroxyl aluminum ion, the adsorption is mainly a relatively weak electrostatic effect. In addition, there is a superposition section in the midst of the titration curves of $\mathrm{Cl}^{-}, \mathrm{Br}^{-}$and $\mathrm{I}^{-}$(see Figure $4(\mathrm{~A})$ ), which indicates that the effects of $\mathrm{Cl}^{-}, \mathrm{Br}^{-}$and $\mathrm{I}^{-}$are all comparatively slight. 
However, excessive $\mathrm{Cl}^{-}$dosage can also change the coordination environment of $\mathrm{Al}^{3+}$ and inhibit the further hydrolysis and polymerizing of $\mathrm{Al}^{3+}$.

2) The higher the concentration of $\mathrm{NaF}$, the higher the initial $\mathrm{pH}$ values of solutions, and the larger the changes of the curves shapes obtained. It has been observed that the three critical points shift to the left little by little until they disappear with the increasing addition of $\mathrm{NaF}$, and the $\mathrm{pH}$ value increases gradually. When $\mathrm{NaF}$ concentration is enough to form $\mathrm{AlF}_{6}$ completely, $\mathrm{NaOH}$ which was added later makes the $\mathrm{pH}$ of solution not to fluctuate after a rapid growth, and behaves as a horizontal line (see Figure 4 (B)). In this case, we can only find the first critical point. However, hydroxyl aluminum just exists as mononuclear Al species. The presence of $\mathrm{F}$ seriously obstructs the hydrolysis-polymerization course of Al salt solution [16, 22].

\section{Effects of the silicate radical}

As a weak acid, silicic acid not only lowers the $\mathrm{pH}$ value of the solution, but also consumes some of the $\mathrm{OH}^{-}$that is used in the hydrolysis-polymerization of $\mathrm{Al}^{3+}$ in the titration course, which makes the conditions of the polymerization of $\mathrm{Al}$ (III) and silicic acid all change. At the same time, the polynuclear silicic acid has a certain chelation (complexation) and adsorption on $\mathrm{Al}^{3+}$, which makes the interaction among the hydrolysis-polymerization products of polynuclear silicic acid and $\mathrm{Al}$ ion become rather complicated [23], which affects the hydrolysispolymerization mechanism of $\mathrm{Al}^{3+}$, the size, the structure, the distribution form and the transformation law of the hydrolysis-polymerization products [23, 24]. The strength of the interaction depends on the $\mathrm{SiO}_{3}{ }^{2-} / \mathrm{Al}^{3+}$ mole ratio. In the experiment, $0.1 \mathrm{M}$ and $0.01 \mathrm{M} \mathrm{Na}_{2} \mathrm{SiO}_{3}$ solutions were prepared by dissolving $\mathrm{Na}_{2} \mathrm{SiO}_{3}$ in the $0.1 \mathrm{M} \mathrm{NaOH}$ solution, respectively, then using them to titrate $25 \mathrm{~mL} 0.05 \mathrm{M} \mathrm{AlCl}_{3}$ solution, respectively, and the corresponding titration curves are shown in Figure 5.

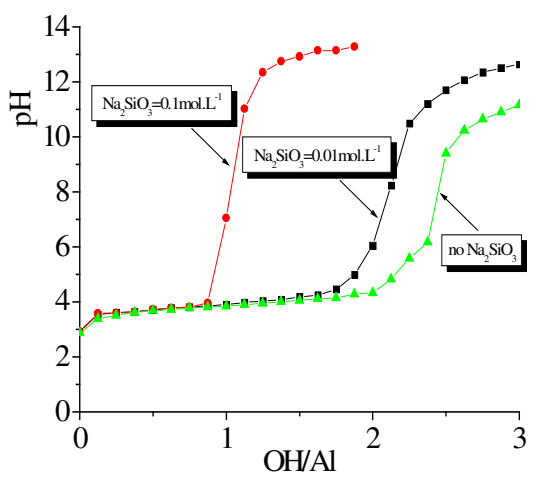

Figure 5. Effect of the soluble silicate concentration on the $\mathrm{Al}$ species and the titration curves $\left(\mathrm{AlCl}_{3}=0.05 \mathrm{M}, \mathrm{NaOH}=0.1 \mathrm{M}\right)$.

It can be seen from this figure that:

1) There is a great effect of $\mathrm{SiO}_{3}{ }^{2-}$ on the second critical point $n_{\mathrm{B}}$ and the third critical point $n_{C}$, i.e., it is extremely great on the formation of polynuclear $\mathrm{Al}$ species $\mathrm{Al}_{\mathrm{b}}$ and gel species $\mathrm{Al}_{\mathrm{c}}$ [25], on the contrary, slight on the first critical point $\mathrm{n}_{\mathrm{A}}$ (see Table 3 ). The higher the concentration of $\mathrm{SiO}_{3}{ }^{2-}$, the smaller the $\mathrm{n}_{\mathrm{B}}$ and $\mathrm{n}_{\mathrm{C}}[26]$, the more the intervals of region II and region III shift forward to region I. After that, it is impossible to detect polynuclear Al species when the concentration of silicic radical reaches a certain extent [27]. For the $0.1 \mathrm{M}$ and $0.01 \mathrm{M} \mathrm{Na}_{2} \mathrm{SiO}_{3}$ 
solutions, the critical points $\mathrm{n}_{\mathrm{B}}$ are 0.8 and 1.5 , respectively, the mole ratios of $\mathrm{SiO}_{3}{ }^{2-} / \mathrm{Al}^{3+}$ are 8.0 and 1.5. From the Figure 5, it seems that $\mathrm{SiO}_{3}{ }^{2-}$ obstructs the hydrolysis and polymerization of $\mathrm{Al}^{3+}$ obviously when $\mathrm{SiO}_{3}{ }^{2-} / \mathrm{Al}^{3+} \geq 1.5$, and it obstructs the polymerization of $\mathrm{Al}^{3+}$ completely at the time when $\mathrm{SiO}_{3}{ }^{2-} / \mathrm{Al}^{3+} \geq 8.0$.

2) On increasing the concentration of $\mathrm{SiO}_{3}{ }^{2-}$, the $\mathrm{pH}$ vs $\mathrm{n}$ curve in region III becomes steeper and steeper, and the range of $\mathrm{OH} / \mathrm{Al}$ mole ratio in which the large-polynuclear $\mathrm{Al}$ species exists is narrower and narrower, furthermore, the $\mathrm{pH}$ increases rapidly simultaneous. It is likely that in the presence of a small quantity of silicic radical, the $\mathrm{Al}$ species in partly neutralized $\mathrm{Al}^{3+}$ solution are mainly in the form of small polymers however when the concentration of silicic radical reach a certain high level, it will cause the polymerization of silicic acid and the formation of higher aggregates as a result of the reaction between the polynuclear silicic acid and the product of hydrolysis-polymerization of $\mathrm{Al}^{3+}$ ions [28].

Table 3. Effects of the $\mathrm{Na}_{2} \mathrm{SiO}_{3}$ consumption on the critical points of the titration curves $\left(\mathrm{AlCl}_{3}=0.05 \mathrm{M}\right.$, $\mathrm{NaOH}=0.1 \mathrm{M})$.

\begin{tabular}{|c|c|c|c|c|c|c|}
\hline \multirow{2}{*}{$\begin{array}{c}\text { Concentration } \\
\text { of } \mathrm{Na}_{2} \mathrm{SiO}_{3}(\mathrm{M})\end{array}$} & \multicolumn{2}{|c|}{$\begin{array}{c}\text { First critical } \\
\text { point }\end{array}$} & \multicolumn{2}{c|}{$\begin{array}{c}\text { Second critical } \\
\text { point }\end{array}$} & \multicolumn{2}{c|}{$\begin{array}{c}\text { Third critical } \\
\text { point }\end{array}$} \\
\cline { 2 - 7 } & $\mathrm{n}_{\mathrm{A}}$ & $\mathrm{pH}_{\mathrm{A}}$ & $\mathrm{n}_{\mathrm{B}}$ & $\mathrm{pH}_{\mathrm{B}}$ & $\mathrm{n}_{\mathrm{C}}$ & $\mathrm{pH}$ \\
\hline 0 & 0.19 & 3.9 & 2.7 & 4.5 & 3.0 & 9.6 \\
\hline 0.01 & 0.11 & 3.5 & 1.9 & 4.3 & 2.3 & 11.0 \\
\hline 0.1 & 0.12 & 3.5 & 0.8 & 3.9 & 1.2 & 12.3 \\
\hline
\end{tabular}

Effects of the organic acid radical

Similar to many inorganic anions, there is competitive coordination between soluble organic acid radical anions and $\mathrm{OH}^{-}$. It is clear that organic acid radicals can react with aluminium and produce various organo-aluminum complex, which can obstruct or delay the hydrolytic reaction of $\mathrm{Al}^{3+}$ [5, 28-33], and even the polynuclear $\mathrm{Al}$ species can not be formed [27, 34]. In particular, the inhibition capability of the different kinds of organic acid radicals is dissimilar to the hydrolysis-polymerization course of $\mathrm{Al}^{3+}$. It is principally disturbed by three aspects [22]: (1) the proportion of organic acid radicals to $\mathrm{Al}^{3+}$; (2) the acidity of organic acid; (3) the stability constant of the complex produced by organic acid radicals and $\mathrm{Al}^{3+}$. The effects of the concentration of $\mathrm{C}_{2} \mathrm{O}_{4}{ }^{2-}$ radical on the critical point of the base titration curve for Al solution are shown in Table 4. The different concentration of sodium citrate $\left(\mathrm{Na}_{3} \mathrm{C}_{6} \mathrm{H}_{5} \mathrm{O}_{7}\right)$, sodium tartrate $\left(\mathrm{Na}_{2} \mathrm{C}_{4} \mathrm{H}_{4} \mathrm{O}_{6}\right)$ and sodium oxalate were added to the $\mathrm{AlCl}_{3}$ solution, respectively, and then regulated its $\mathrm{pH}$ value to the initial $\mathrm{pH}$ value of $\mathrm{AlCl}_{3}$ with $\mathrm{HCl}$, at last, these $\mathrm{AlCl}_{3}$ solutions were titrated with the base. Therefore, the titration curves obtained from this experiment which are shown in Figure 6 and Table 4, from which it can be concluded that:

1) The addition of organic acid radical decreases the concentration of Al taking part in the hydrolysis-polymerization, which causes the first region to be broadened. The further hydrolysis and polymerizing of $\mathrm{Al}^{3+}$ will be inhibited when the organic acid radical is in high level. In this case, only the first critical point can be found, the other critical points followed can not be distinguished.

2) The shapes of the titration curves can be distinguished with different dosage of organic acid salt, the higher the concentration, the greater the initial $\mathrm{pH}$ value of the solution, the serious aberrance in the shape of curve obtained, as well as the greater effects on the hydrolysispolymerization course of $\mathrm{Al}^{3+}$. With the increasing amount of organic acid radical, the three critical points shift to the left gradually until disappear. When the mole ratio of the organic acid radicals to $\mathrm{Al}^{3+}$ is $1: 1$, there is quite an effect on the titration curves. In the meantime, the hydrolysis-polymerization course of Al salt solution was badly obstructed by the organic acid

Bull. Chem. Soc. Ethiop. 2008, 22(2) 
radicals. Observed from the changes of the titration curves, in the same mole ratio of organic acid radicals to $\mathrm{Al}^{3+}$, the order according to the degree of their effects as follows: citrate > oxalate $>$ tartrate. Furthermore, the mechanism why organic ligand could obstruct the hydrolysis-polymerization of $\mathrm{Al}^{3+}$ is that the complexation reaction occurs between the organic acid radicals and the polynuclear $\mathrm{Al}$ species which are in kinetic equilibrium that makes the hydroxyl-bridges among Al atoms of polynuclear Al be destroyed. Therefore, in the presence of organic acid, the forms of aluminum as the mononuclear $\mathrm{Al}$ and the oligomers can not be agglomerated [5], and the crystalloid $\mathrm{Al}(\mathrm{OH})_{3}$ can also not be formed [22].

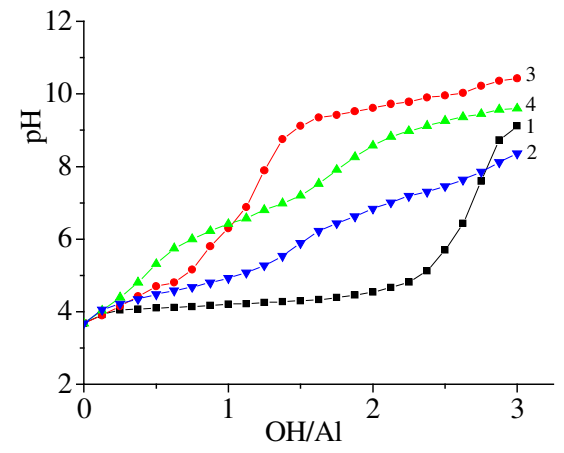

Figure 6. Effects of organic acid radical on the titration curves and their critical points. $\left(\mathrm{AlCl}_{3}=\right.$ $0.005 \mathrm{M}$, the mole ratio of organic acid radical: $\left.\mathrm{Al}^{3+}=1: 1, \mathrm{NaOH}=0.01 \mathrm{M}\right) .1$, no organic acid radical; 2 , sodium citrate; 3 , sodium tartrate; 4 , sodium oxalate.

Table 4. Effects of the $\mathrm{C}_{2} \mathrm{O}_{4}{ }^{2-}$ concentration on the critical points of titration curves $\left(\mathrm{AlCl}_{3}=0.005 \mathrm{M}\right.$, $\mathrm{NaOH}=0.01 \mathrm{M})$.

\begin{tabular}{|c|c|c|c|c|c|c|}
\hline $\begin{array}{c}\text { Concentration of } \\
\mathrm{C}_{2} \mathrm{O}_{4}{ }^{2-}(\mathrm{M})\end{array}$ & \multicolumn{2}{|c|}{$\begin{array}{c}\text { First critical } \\
\text { point }\end{array}$} & \multicolumn{2}{c|}{$\begin{array}{c}\text { Second critical } \\
\text { point }\end{array}$} & \multicolumn{2}{c|}{$\begin{array}{c}\text { Third critical } \\
\text { point }\end{array}$} \\
\cline { 2 - 7 } & $\mathrm{n}_{\mathrm{A}}$ & $\mathrm{pH}_{\mathrm{A}}$ & $\mathrm{n}_{\mathrm{B}}$ & $\mathrm{pH}_{\mathrm{B}}$ & $\mathrm{n}_{\mathrm{C}}$ & $\mathrm{pH}_{\mathrm{C}}$ \\
\hline 0.5 & 0.38 & 8.2 & without & without & without & without \\
\hline 0.01 & 0.12 & 4.2 & 1.1 & 4.4 & without & without \\
\hline 0.005 & 0.13 & 4.1 & 1.5 & 4.7 & 1.9 & 7.16 \\
\hline
\end{tabular}

\section{AKNOWLEDGEMENTS}

This project was financially supported by the Natural Science Foundation of China (No. 30771696), the Natural Science Foundation of Zhejiang Province (No. Y407318), and the Science and Technology Plan of Huzhou (No. 2007YS18).

\section{REFERENCES}

1. Hunter, D.; Ross, D.S. Science 1991, 251, 1056.

2. Kerven, G.L.; Larsen, P.L.; Blamey, F.P.C. Soil Sci. Soc. Am. J. 1995, 59, 765.

3. Comin, J.J.; Barloy, J.; Bourrie, G. Europ. J. Agron. 1999, 11, 115.

4. Sposito, G. The Environmental Chemistry of Aluminum, 2nd ed., CRC Press: Boca Raton, Florida; 1995; p 87. 
5. Wang, C.Y.; Bi, S.P. ACS Symp. Ser. American Chemical Society: Washington, DC; 2002; 822, 246.

6. Phillips, B.L.; Lee, A.; Casey, W.H. Geochim. Cosmochim. Acta 2003, 67, 2725.

7. Gürses, A.; Yalçin, M.; Dogar, C. Water, Air, Soil Pollut. 2003, 146, 297.

8. Nandy, T.; Shastry, S.; Pathe, P.P.; Kaul, S.N. Water, Air, Soil Pollut. 2003, 148, 15.

9. EL-Masry, M.H.; Sadek, O.; Mekhemer, W.K. Water, Air, Soil Pollut. 2004, 158, 373.

10. Rustad, J.R.; Loring, J.S.; Casey, W.H. Geochim. Cosmochim. Acta 2004, 68, 3011.

11. Irving, H.M.; Miles, M.G.; Pettit, L.D. Anal. Chim. Acta 1967, 38, 475.

12. Wang, D.S.; Wei, S.; Yi, X. Colloids Surf. A: Physicochem. Eng. Aspects 2004, 243, 1.

13. Duan, J.; Gregory, J. Adv. Colloid Interface Sci. 2003, 100-102, 475.

14. Bi, S.P.; Wang, C.Y.; Cao, Q.; Zhang, C.H. Coord. Chem. Rev. 2004, $248,441$.

15. Stol, R.J.; van Helden, A.K.; Bruyn, P.L. J. Colloid Interface Sci. 1976, 57, 115.

16. Letterman, R.D.; Asolekar, S.R. Wat. Res. 1990, 24, 931.

17. Hek, H.; Stol, R.J.; Bruyn, P.L. J. Colloid Interface Sci. 1978, 64, 72.

18. Busch, M.; Seubert, A. Anal. Chim. Acta 1999, 399, 223.

19. Phillips, B.L.; Casey, W.H.; Karlsson, M. Nature 2000, 404, 379.

20. Phillips, B.L.; Casey, W.H.; Karlsson, M. Environ. Sci. Technol. 2000, 34, 3242.

21. Wang, S.L.; Wang, M.K.; Tzou, Y.M. Colloids Surf. A: Physicochem. Eng. Aspects 2003, 231, 143.

22. Hsu, P.H. Soil Chemical Florilegium, Science Press: Beijing; 1986; p 19.

23. Gao, B.Y.; Yue, Q.Y.; Wang, Z.S.; Tang, H.X. Environ. Chem. (Chinese) 2000, 19, 1.

24. Tang, Y.X.; Yang, K.; Wu, S.Q. Environ. Chem. (Chinese) 1997, 16, 60.

25. Boisvert, J.P.; Jolicoeur, C. Colloids Surf. A: Physicochem. Eng. Aspects 1999, 155, 161.

26. Browne, B.A.; Driscoll, C.T. Environ. Sci. Technol. 1992, 27, 915.

27. Larsen, P.L.; Kerven, G.L.; Bell, L.C. Effects of silica acid on the chemistry of monomeric and polymeric $\left(A l_{13}\right)$ aluminum species in synthetic soil solutions, $3^{\text {rd }}$ International Symposium on Plant Soil interactions at Low pH, Dordrecht; 1992; p 1.

28. Gao, B.Y.; Li, C.P. Environ. Chem. (Chinese) 1993, 12, 268.

29. Krishnamurti, G.S.R.; Wang, M.K.; Huang, P.M. Clays and Clay Miner. 1999, 47, 658.

30. Tombacz, E.; Filipcsei, G.; Szekeres, M. Colloids Surf. A: Physicochem. Eng. Aspects 1999, 151, 233.

31. Narayanan, R.; Laine, R.M. J. Mater. Chem. 2000, 10, 2097.

32. Marilyne, V.S.; Guy, B. J. Inorg. Biochem. 2001, 85, 143.

33. Changui, C.; Stone, W.E.E.; Vielvoye, L. J. Chem. Soc. Dalton Trans. 1990, 1990, 1723.

34. Masion, A.; Thomas, F.; Tchoubar, D. Langmuir 1994, 10, 4353. 